\section{Commentary: Expertise in fitting square pegs in round holes}

\author{
Fraser D. Rubens, MD, MSc, FACS, FRCSC
}

In this technical treatise, Yang $^{1}$ has provided us a detailed description of his novel approach to manage patients with small aortic roots undergoing aortic valve replacement. Whereas some surgeons dismiss the concerns of implanting small valves in this situation with the potential of patientprosthesis mismatch, most of us avoid this complication by using some form of root enlargement, such as Nicks or Manouguian procedures or by consideration of a modified Bentall as an alternative.

Yang has clearly described the sequential steps to support this approach such that a practicing, experienced surgeon could attempt this safely. It is not clear to this reviewer that the annulus is actually enlarged with this approach. The proposed incision is an inverted "T," and the patch is essentially tailored such that its width (after suturing) is the same measure as the horizontal portion of the " $T$ " shown in the central picture. In the Nicks procedure, the incision and subsequent placement of the patch actually increases this horizontal measure, explaining the mechanism for true enlargement. Regardless, Yang's strategy appears to work; I suspect that it allows the operator to safely tilt the valve when suturing in the region of the commissure between the left and the noncoronary. The advantage of the approach is that it allows insertion of a larger valve without compromise of the left coronary ostium, arguably by modest tilting of the valve. This alignment is enabled by the mandatory 90-degree clockwise rotation of the left coronary ostium. The surgeon must be aware of the arc of rotation of the coronary and recognize the potential risk, particularly if there is some degree of calcification of the

\footnotetext{
From the Division of Cardiac Surgery, University of Ottawa Heart Institute, Ottawa, Ontario, Canada.

Disclosures: The author reported no conflicts of interest.

The Journal policy requires editors and reviewers to disclose conflicts of interest and to decline handling or reviewing manuscripts for which they may have a conflict of interest. The editors and reviewers of this article have no conflicts of interest.

Received for publication Nov 1, 2020; revisions received Nov 1, 2020; accepted for publication Nov 6, 2020; available ahead of print Nov 25, 2020.

Address for reprints: Fraser D. Rubens, MD, MSc, FACS, FRCSC, Ottawa Heart Institute, 40 Ruskin St, Ottawa, Ontario K1Y 4W7, Canada (E-mail: frubens@ ottawaheart.ca).

JTCVS Techniques 2021;5:19

2666-2507

Copyright (C) 2020 The Authors. Published by Elsevier Inc. on behalf of The American Association for Thoracic Surgery. This is an open access article under the CC BY-NCND license (http://creativecommons.org/licenses/by-nc-nd/4.0/).

https://doi.org/10.1016/j.xjtc.2020.11.021
}

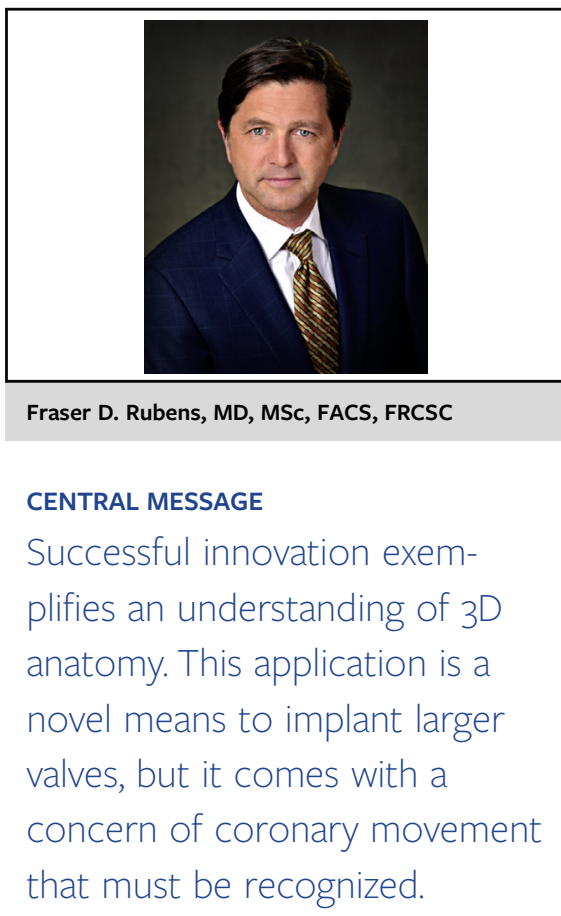

left main, in which case rotation without sufficient mobilization could be accompanied by lumen compromise.

As more and more straightforward aortic valves with normal preoperative annulus get gobbled up by the transaortic valve replacement train, the relative proportion of patients with small annuli will continue to increase and we will see more of these patients. Yang's strategy offers another arrow to our strategic quiver. Its use should be cautiously encouraged with the caveat that we must fully understand the root and coronary manipulations that accompany this technique. I hope to see collaboration with his radiology colleagues to better delineate the anatomic changes that ensue from this strategy, particularly if any of these patients go down the path of valve-in-valve transaortic valve replacement procedures in the future.

\section{Reference}

1. Yang B. A novel simple technique to enlarge the aortic annulus by two valve sizes. J Thorac Cardiovasc Surg Tech. 2021;5:13-6. 